\title{
The Effectiveness of Decontamination Products in the Nuclear Medicine Department
}

\author{
Nicholas Ruhman, Vesper Grantham, RT(N), CNMT, and Chris Martin, RT(N), CNMT \\ Department of Medical Imaging and Radiation Sciences, College of Allied Health, University of Oklahoma Health Sciences Center, \\ Oklahoma City, Oklahoma
}

\begin{abstract}
This study assesses the effectiveness of using everyday cleaning agents for the radioactive decontamination of wet 99mTc-pertechnetate spills in the nuclear medicine department. Methods: Six cleaning agents (water, water and soap, alcohol, bleach, a commercial glass cleaner, and a commercial decontaminating agent) were analyzed for decontamination effectiveness for a wide range of surfaces (Formica, vinyl, vinyl-polyester, plastic, rubber, and polyester). Results: Within the experiment, the contamination was removed to radioactivity levels of less than $1 \%$ of the original contamination level. Conclusion: The results indicate that for a range of surfaces, the investigated commercially available cleaning agents had little or no benefit over plain tap water when used to decontaminate ${ }^{99 m}$ Tc-pertechnetate spills.
\end{abstract}

Key Words: wet spills; decontamination; pertechnetate contamination

J Nucl Med Technol 2010; 38:191-194

DOI: 10.2967/jnmt.110.076919

\section{$\mathbf{R}$} adioactive contamination can be a relatively common occurrence in a nuclear medicine department. When equipment is contaminated with radioactivity, cleanup is necessary to restore the utility of the equipment. Contamination also leads to exposure of employees working in the area. Therefore, radioactive contamination needs to be recognized and removed in a quick and effective manner to restore full productivity to a department and maintain safe radiation practices.

There is limited research pertaining to the decontamination of minor wet radioactive spills on surfaces. According to a regulatory guide of the U.S. Nuclear Regulatory Commission, a minor radioactive spill of pertechnetate is one that results in $3.7 \mathrm{MBq}(100 \mu \mathrm{Ci})$ or less $(1)$. A minor spill has also been described as less than 50,000 counts per minute $(\mathrm{cpm})$ at $30.5 \mathrm{~cm}$ (12 in) in a study by Mosman

\footnotetext{
Received Mar. 11, 2010; revision accepted Aug. 27, 2010.

For correspondence or reprints contact: Vesper Grantham, University of Oklahoma Health Sciences Center, 1200 N. Stonewall, AHB 3021, Oklahoma City, OK 73117.

E-mail: vesper-grantham@ouhsc.edu

COPYRIGHT @ 2010 by the Society of Nuclear Medicine, Inc.
}

et al. (2). For the purpose of the current study, $3.7 \mathrm{MBq}$ $(100 \mu \mathrm{Ci})$ will be used to indicate a minor spill.

Research has established the effectiveness of many cleaners in the decontamination of minor radioactive spills on human skin. The results of this previous research indicated that the commercially available decontaminating agents Radiacwash (Biodex Medical Systems) and Isoclean (Isolab) have little to no benefit over common substances such as soap and water when used on the skin. However, this research also stated that these agents may be of greater benefit when used on countertops or glassware (3).

The purpose of this study was to determine the most appropriate agent to use when cleaning a wet radioactive spill from surfaces common in a nuclear medicine department. The research design examines the hypothesis that common cleaners such as soap and water are as effective as commonly used commercial decontaminating agents, which are more costly.

\section{MATERIALS AND METHODS}

Six different cleaning substances (water, water and soap, alcohol, bleach, Windex [S.C. Johnson \& Son, Inc.], and Radiacwash) were used to decontaminate a controlled simulated wet radioactive spill on 6 different surfaces common to the nuclear medicine department. These surfaces included Formica (Formica Corp.), which makes up the surface of many countertops and injection stands in the nuclear medicine department; vinyl, the material of common floor tile; vinyl-polyester, common padding material on imaging beds; grooved plastic, which is found on some imaging tables and computers; rubber, representative of the sole of technologists' shoes; and polyester, the material of laboratory coats. Separate pieces of each surface were used for individual spills so that no contamination remained on any of the surfaces. Each surface was assessed for background and any prior radioactive contamination. Absorbent pads were placed under each surface to prevent spread of contamination, and these were appropriately discarded and replaced after each spill.

To perform the controlled wet radioactive contamination spill, we diluted approximately $18.5 \mathrm{MBq}(500 \mu \mathrm{Ci})$ of ${ }^{99 \mathrm{~m}} \mathrm{Tc}$-pertechnetate $\left({ }^{99} \mathrm{TcO}_{4}\right)$ into a $12-\mathrm{mL}$ syringe of normal saline, assayed the solution in a dose calibrator, 
TABLE 1

Radiation Exposure Data $(\mathrm{mR} / \mathrm{h})$ for Before Decontamination and After Decontamination

\begin{tabular}{|c|c|c|c|c|c|c|c|}
\hline Surface & Time & Water & Soap and water & Bleach & Alcohol & Windex & Radiacwash \\
\hline Formica & $\begin{array}{l}\text { Before } \\
\text { After }\end{array}$ & $\begin{array}{l}20 \\
0.08\end{array}$ & $\begin{array}{l}15 \\
0.09\end{array}$ & $\begin{array}{l}16 \\
0.1\end{array}$ & $\begin{array}{l}17 \\
0.08\end{array}$ & $\begin{array}{c}15.5 \\
0.09\end{array}$ & $\begin{array}{l}16 \\
0.07\end{array}$ \\
\hline Vinyl tile & $\begin{array}{l}\text { Before } \\
\text { After }\end{array}$ & $\begin{array}{l}19 \\
0.04\end{array}$ & $\begin{array}{c}14.7 \\
0.04\end{array}$ & $\begin{array}{l}17 \\
0.05\end{array}$ & $\begin{array}{l}13 \\
0.06\end{array}$ & $\begin{array}{l}17 \\
0.07\end{array}$ & $\begin{array}{l}14 \\
0.12\end{array}$ \\
\hline Vinyl or polyester bed pads & $\begin{array}{l}\text { Before } \\
\text { After }\end{array}$ & $\begin{array}{c}16.5 \\
0.11\end{array}$ & $\begin{array}{l}15 \\
0.17\end{array}$ & $\begin{array}{l}14 \\
0.09\end{array}$ & $\begin{array}{c}15.5 \\
0.12\end{array}$ & $\begin{array}{c}16.5 \\
0.08\end{array}$ & $\begin{array}{l}16 \\
0.06\end{array}$ \\
\hline Plastic with grooves & $\begin{array}{l}\text { Before } \\
\text { After }\end{array}$ & $\begin{array}{c}11.5 \\
0.03\end{array}$ & $\begin{array}{l}8 \\
0.04\end{array}$ & $\begin{array}{l}16 \\
0.06\end{array}$ & $\begin{array}{c}14.5 \\
0.04\end{array}$ & $\begin{array}{c}16.5 \\
0.07\end{array}$ & $\begin{array}{c}12.5 \\
0.06\end{array}$ \\
\hline Rubber sole & $\begin{array}{l}\text { Before } \\
\text { After }\end{array}$ & $\begin{array}{c}12.5 \\
0.06\end{array}$ & $\begin{array}{l}7 \\
0.12\end{array}$ & $\begin{array}{l}9.5 \\
0.06\end{array}$ & $\begin{array}{c}11.5 \\
0.07\end{array}$ & $\begin{array}{l}9 \\
0.04\end{array}$ & $\begin{array}{l}13 \\
0.04\end{array}$ \\
\hline Laboratory coat & $\begin{array}{l}\text { Before } \\
\text { After }\end{array}$ & $\begin{array}{l}18 \\
3.5\end{array}$ & $\begin{array}{r}11 \\
6\end{array}$ & $\begin{array}{r}14.5 \\
4.5\end{array}$ & $\begin{array}{r}17 \\
7\end{array}$ & $\begin{array}{r}19.5 \\
4.5\end{array}$ & $\begin{array}{c}13.5 \\
5\end{array}$ \\
\hline
\end{tabular}

and spilled $1 \mathrm{~mL}$ of the solution, or approximately $1.5 \mathrm{MBq}$ $(41.6 \mu \mathrm{Ci})$. Once the controlled contamination occurred, an exposure reading was taken $1.27 \mathrm{~cm}(0.5 \mathrm{in})$ from the surface of the wet spill with a Geiger-Mueller survey meter, and the highest reading was recorded in $\mathrm{mR} / \mathrm{h}$. To more sensitively assess the contamination characteristics, the wet spill area was wiped with a cotton swab, and each wipe was counted in a Cobra II Auto- $\gamma$-well counter (Packard) for $1 \mathrm{~min}$. These values were recorded as the predecontamination exposure $(\mathrm{mR} / \mathrm{h})$ and predecontamination wipe (cpm), to document the contamination level for each spill on each surface.

After the initial contamination levels were documented, each simulated spill was cleaned using $2 \times 2$ gauze pads and $1 \mathrm{~mL}$ of the selected cleaning agent for 10-s increments (total, $30 \mathrm{~s}$; a new gauze pad for each increment). An automatic pipette was used to disperse the cleaning solutions in $1-\mathrm{mL}$ aliquots, to maintain control over the amount of each cleaner used.

During and after decontamination, 4 additional data values were obtained and documented for each wet spill. These included 10-, 20-, and 30-s wipes (cpm) and postdecontamination exposure $(\mathrm{mR} / \mathrm{h})$ taken at $1.27 \mathrm{~cm}$ (0.5 in) from the surface of the spill.

\section{RESULTS}

Each of the 6 readings (predecontamination exposure, postdecontamination exposure, predecontamination wipe,

TABLE 2

Radiation Exposure Data (cpm) for Before Decontamination and After Decontamination

\begin{tabular}{|c|c|c|c|c|c|c|c|}
\hline Surface & Time & Water & Soap and water & Bleach & Alcohol & Windex & Radiacwash \\
\hline \multirow[t]{4}{*}{ Formica } & Before & 308,674 & 500,249 & 383,839 & 706,744 & 149,773 & 150,644 \\
\hline & After & $10 \mathrm{~s}, 150$ & 10 s, 266 & 10 s, 202 & $10 \mathrm{~s}, 303$ & 10 s, 247 & $10 \mathrm{~s}, 191$ \\
\hline & & $20 \mathrm{~s}, 53$ & $20 s, 59$ & $20 s, 59$ & 20 s, 90 & 20 s, 78 & 20 s, 68 \\
\hline & & $30 \mathrm{~s}, 2$ & $30 \mathrm{~s}, 24$ & $30 \mathrm{~s}, 13$ & $30 \mathrm{~s},-4$ & $30 \mathrm{~s}, 98$ & $30 \mathrm{~s}, 11,111$ \\
\hline \multirow[t]{4}{*}{ Vinyl tile } & Before & $1,001,713$ & 523,735 & $2,472,790$ & 1,697,206 & 623,491 & $1,025,161$ \\
\hline & After & 10 s, 276 & $10 \mathrm{~s}, 500$ & 10 s, 660 & $10 \mathrm{~s}, 1,570$ & 10 s, 287 & 10 s, 625 \\
\hline & & 20 s, 35 & 20 s, 99 & 20 s, 90 & 20 s, 325 & 20 s, 50 & 20 s, 192 \\
\hline & & $30 \mathrm{~s}, 25$ & $30 \mathrm{~s}, 48$ & $30 \mathrm{~s}, 39$ & $30 \mathrm{~s}, 74$ & $30 \mathrm{~s}, 40$ & 30 s, 43,226 \\
\hline \multirow[t]{4}{*}{ Vinyl or polyester bed pads } & Before & 328,417 & $3,103,071$ & $3,570,187$ & $2,106,447$ & 391,131 & 610,695 \\
\hline & After & $10 \mathrm{~s}, 90$ & $10 \mathrm{~s}, 722$ & $10 \mathrm{~s}, 721$ & $10 \mathrm{~s}, 1,326$ & $10 \mathrm{~s}, 126$ & 10 s, 322 \\
\hline & & $20 \mathrm{~s}, 21$ & $20 \mathrm{~s}, 110$ & 20 s, 70 & 20 s, 107 & $20 \mathrm{~s}, 5$ & 20 s, 46 \\
\hline & & $30 \mathrm{~s}, 20$ & $30 \mathrm{~s}, 8$ & $30 \mathrm{~s}, 31$ & $30 \mathrm{~s}, 30$ & $30 s,-2$ & $30 \mathrm{~s}, 12$ \\
\hline \multirow[t]{4}{*}{ Plastic with grooves } & Before & 627,252 & 448,076 & 993,809 & 361,192 & 439,388 & 197,915 \\
\hline & After & $10 \mathrm{~s}, 173$ & 10 s, 277 & 10 s, 269 & $10 \mathrm{~s}, 157$ & $10 \mathrm{~s}, 215$ & 10 s, 1,188 \\
\hline & & 20 s, 46 & $20 \mathrm{~s}, 74$ & 20 s, 69 & 20 s, 90 & $20 s, 53$ & 20 s, 299 \\
\hline & & $30 \mathrm{~s}, 44$ & 30 s, 58 & $30 \mathrm{~s}, 57$ & 30 s, 57 & $30 \mathrm{~s}, 62$ & $30 \mathrm{~s}, 68$ \\
\hline \multirow[t]{4}{*}{ Rubber sole } & Before & 389,195 & $2,058,484$ & 634,797 & $1,197,365$ & 727,611 & 310,338 \\
\hline & After & 10 s, 238 & 10 s, 680 & $10 \mathrm{~s}, 425$ & 10 s, 290 & 10 s, 339 & $10 \mathrm{~s}, 8,790$ \\
\hline & & 20 s, 62 & $20 \mathrm{~s}, 131$ & 20 s, 318 & 20 s, 104 & 20 s, 128 & 20 s, 148 \\
\hline & & $30 \mathrm{~s}, 3$ & 30 s, 27 & 30 s, 86 & $30 \mathrm{~s}, 6$ & $30 \mathrm{~s}, 21$ & $30 \mathrm{~s}, 119$ \\
\hline \multirow[t]{4}{*}{ Laboratory coat } & Before & 36,975 & 12,933 & 13,554 & 19,121 & 47,560 & 16,836 \\
\hline & After & 10 s, 949 & $10 \mathrm{~s}, 11,590$ & $10 \mathrm{~s}, 3,949$ & 10 s, 17,321 & $10 \mathrm{~s}, 4,111$ & 10 s, 5,229 \\
\hline & & 20 s, 7,295 & 20 s, 3,744 & 20 s, 342 & $20 \mathrm{~s}, 11,487$ & $20 \mathrm{~s}, 12,461$ & 20 s, 14,751 \\
\hline & & 30 s, 792 & $30 \mathrm{~s}, 6,423$ & $30 \mathrm{~s}, 1,414$ & 30 s, 7,968 & 30 s, 8,791 & 30 s, 9,976 \\
\hline
\end{tabular}


TABLE 3

Averages for Percentage of Removed Contamination on Each Surface

\begin{tabular}{ccccccc}
\hline Exposure after... & Formica countertop & Tile floor & Vinyl bed & Grooved plastic & Rubber sole & Laboratory coat \\
\hline 10 s of cleaning $(\mathrm{cpm})$ & 99.9 & 99.9 & 99.9 & 99.8 & 99.5 & 58.2 \\
20 s of cleaning $(\mathrm{cpm})$ & 99.9 & 99.9 & 99.9 & 99.8 & 99.9 & 62.6 \\
30 s of cleaning $(\mathrm{cpm})$ & 98.7 & 99.2 & 99.9 & 99.9 & 99.9 & 69.7 \\
Final $(\mathrm{mR} / \mathrm{h})$ & 99.5 & 99.9 & 99.3 & 99.9 & 99.3 & 65.6 \\
\hline
\end{tabular}

and 10-, 20-, and 30-s wipes) was documented. The exposure data for the predecontamination and postdecontamination of each surface with each cleaner are documented in Table 1, and the wipe test data for each surface and each cleaner are documented in Table 2.

The percentage radioactive contamination remaining was calculated for each wet spill in both exposure and activity using the following formula: $\%$ remaining $=$ (postcleaning wipe or exposure/precleaning wipe or exposure $) \times 100$. The averages for the percentage of contamination removed for all of the cleaners on each surface are recorded in Table 3. Most of the radioactive contamination spills were more than 99\% removed after the first 10 s of cleaning. Predictably, however, the laboratory coat-because of its porous fabric structure-was not as easily cleaned using $10 \mathrm{~s}$ of scrubbing.

Each individual cleaner was also assessed. Table 4 reports the averages of the percentage of removed contamination on all surfaces for each cleaner. The laboratory coat data were excluded from these calculations. In 2 cases for Radiacwash, the wipe for the third $10 \mathrm{~s}$ of cleaning had a higher reading than the wipes for the first and second $10 \mathrm{~s}$ of cleaning. This higher reading, which could be attributed to inconsistencies in the cleaning and wiping of these surfaces by the researcher, occurred during both the Formica and vinyl tile cleanings.

\section{DISCUSSION}

The results show that Radiacwash has little to no benefit over common cleaning agents when used to remove a wet spill of ${ }^{99} \mathrm{TcO}_{4}$ contamination from everyday surfaces found in the nuclear medicine department. In this study, the assessed cleaners in most cases removed more than $99 \%$ of contamination, demonstrating that minor wet spills may be effectively decontaminated using less specific radioactive cleaning agents. Some agents, such as Radiac- wash, are formulated to decontaminate wide ranges of nuclides using sequestering agents, chelators, carriers, ion exchangers, emulsifiers, solvents, complexers, peptizers, or detergents (4). These agents are much more expensive than tap water because of the contained compounds and may be more appropriate for other radionuclides.

The research experiment was designed to control as many of the extraneous variables as possible. First, the exact amount of radioactive contamination was difficult to control for each simulated contamination spill because of the randomness of radiation and the difficulty in measuring the exact amount of activity per milliliter volume. In an effort to control the amount of contamination, each spill was sampled from the same concentration of ${ }^{99} \mathrm{mcO}_{4}$ diluted in saline and was the same volume. We also tried to eliminate any significant variability in decay by performing each decontamination as quickly as possible in 30-s increments.

Second, there may have been inconsistencies in the wiping or cleaning method for each surface and cleaner, especially concerning the exact motion of the investigator's hand. Cleaning methods included wiping the spills from outside to inside using one $2 \times 2$ gauze pad and $1 \mathrm{~mL}$ of the selected cleaner for $10 \mathrm{~s}$. The 10 -s increments were measured using a stopwatch. Wipes were taken across the diameter of each spill, but this distance may not have been exactly consistent for each wipe. In addition, the pressure applied during each wipe was not specifically measured or controlled.

Spills of short-lived radionuclides may be overlooked in a nuclear medicine department not only because of decay but also because radionuclides will dry over time. However, the drying effect was not investigated here and is recommended for further study.

To eliminate the effect of surface degradation, only new surfaces were used in this experiment. Surfaces change

TABLE 4

Averages for Percentage of Removed Contamination for Each Cleaner*

\begin{tabular}{|c|c|c|c|c|c|c|}
\hline Exposure after... & Soap & Bleach & Alcohol & Radiacwash & Windex & Water \\
\hline $10 \mathrm{~s}$ of cleaning (cpm) & 99.9 & 99.9 & 99.9 & 99.2 & 99.9 & 99.9 \\
\hline $20 \mathrm{~s}$ of cleaning (cpm) & 99.9 & 99.9 & 99.9 & 99.8 & 99.9 & 99.9 \\
\hline $30 \mathrm{~s}$ of cleaning (cpm) & 99.9 & 99.9 & 99.9 & 97.1 & 99.9 & 99.9 \\
\hline Final $(m R / h)$ & 99.3 & 99.6 & 99.6 & 99.7 & 99.6 & 99.7 \\
\hline
\end{tabular}


after many years of use and may be more or less difficult to decontaminate. The use of existing surfaces rather than new ones could provide different results.

Finally, only Radiacwash was investigated as the commercial decontaminating agent. For the investigation results to be more clinically applicable, additional commercial decontaminating agents should also be included in a similar study. This is especially true because of the questionable Radiacwash data for the Formica and vinyl surfaces. Absorbent dry paper materials could also be studied for their effectiveness in wiping up wet spills.

Nuclear medicine technologists are particularly well educated to assist in the management of major and minor radioactive contamination events. Simulation exercises, for both major and minor contamination events, can be essential to an institution's response, performance, and coordination in these situations (5). It is important that nuclear medicine personnel are well educated and practiced in the process of decontamination. This research demonstrates that the use of water or other available cleaning agents may be a sufficient means of removing most wet ${ }^{99} \mathrm{TcO}_{4}$ contamination when identified early.

\section{CONCLUSION}

${ }^{99} \mathrm{TcO}_{4}$ contamination in a nuclear medicine department can be cleaned quickly and effectively using plain tap water. Commercially available decontaminating agents such as Radiacwash offer no observed benefits over any of the cleaners used in this study involving wet contamination spills of ${ }^{99} \mathrm{TcO}_{4}$. Thirty seconds of cleaning with tap water will remove more than $99 \%$ of minor ${ }^{99} \mathrm{mcO}_{4}$ contamination from many surfaces common to a nuclear medicine department.

\section{ACKNOWLEDGMENTS}

We thank Dallas Miller and the Department of Veterans Affairs Medical Center in Oklahoma City, Oklahoma, for assistance in the study design and use of facilities.

\section{REFERENCES}

1. U.S. Nuclear Regulatory Commission. Regulatory Guide 10.8, Revision 2. Guide for the Preparation of Applications for Medical Use Programs. August 1987. Available at: http://www.nrc.gov/reading-rm/doc-collections/reg-guides/general/ rg/. Accessed November 4, 2010.

2. Mosman EA, Peterson LJ, Hung JC, Gibbons RJ. Practical methods for reducing radioactive contamination incidents in the nuclear cardiology laboratory. $\mathrm{J} \mathrm{Nucl}$ Med Technol. 1999;27:287-289.

3. Moore PH, Mettler PA. Skin decontamination of commonly used medical nuclides. J Nucl Med. 1980;21:475-476.

4. Biodex Medical Systems. Radiacwash. Available at: http://www.biodex.com/ radio/radiopharmacy/decontam_100.htm. Accessed October 6, 2010.

5. Schleipman AR, Gerbaudo VH, Castronovo FP. Radiation disaster response: preparation and simulation experience at an academic medical center. $\mathrm{J} \mathrm{Nucl} \mathrm{Med}$ Technol. 2004;32:22-27. 